\title{
GIS-Based Multi-Criteria Decision Analysis for the Sustainable Management of the Nkong Zem Pipe-Borne Water Network: West Region of Cameroon
}

\author{
Elvis Kah*, Ngounnoun Tenkeu Therry, Ndoh Mbue Innocent \\ School of Geology and Mining Engineering, University of Ngaoundere, Ngaoundere, Cameroon \\ Email: *kah_elvis@yahoo.fr, elvis18289@alumni.itc.nl
}

How to cite this paper: Kah, E., Therry, N.T. and Innocent, N.M. (2019) GIS-Based Multi-Criteria Decision Analysis for the Sustainable Management of the Nkong Zem Pipe-Borne Water Network: West Region of Cameroon. Journal of Geographic Information System, 11, 727-746. https://doi.org/10.4236/jgis.2019.116044

Received: September 11, 2019

Accepted: December 24, 2019

Published: December 27, 2019

Copyright $\odot 2019$ by author(s) and Scientific Research Publishing Inc. This work is licensed under the Creative Commons Attribution International License (CC BY 4.0).

http://creativecommons.org/licenses/by/4.0/

\section{c) (i) Open Access}

\begin{abstract}
Access to potable water is a serious problem that plagues most communities in $3^{\text {rd }}$ World countries. Governments to this effect have developed texts governing the water sector that often encourage local participation. Thus, in pursuance of the Sustainable Development Goals (SDGs) set up after 2015 following the failure to achieve the MDGs by the UN, many countries still do not attain the set objectives today. GICABAF (A Common Initiative Group) in 2012 financed the installation of pipe-borne water network in Sa'ah Batsengl'a locality in Nkong Zem Council of West Cameroon. But the problem observed in its management is that no database was put in place to ease its management which cannot guarantee sustainability. This study proposes a computerised database to manage the water network. To conduct this study, a six months internship was carried out with GICAPBAF where GPS was used to track all the pipes and locate other phenomena. Then a set questionnaire was administered to subscribers and managers in order to understand the functioning of the network so as to propose the GIS-AWS. These data collected were then treated and analysed in a GIS software (MapInfo). The generated database was then coupled to a flow simulation model in a distribution network (Epanet) which gave rise to GIS-Epanet. This was realised through the use of plugin GHydraulics of QGis and the MapBasic language of MapInfo. This will enable present and future managers of the project to master the network thereby facilitating the detection of any malfunctioning for prompt reaction. This simply summarises the putting in place of GIS Applied to Water Supply (GIS-AWS).
\end{abstract}

\section{Keywords}

Model, GIS, GIS-AWS, Epanet, Sustainable Management, Nkong Zem, 


\section{Introduction}

Access to safe potable water, sanitation and hygiene are critical for the survival, development and wellbeing of a population. Due to this, Plan International in 2015 spent about 54 million Euros $(35,100,000,000$ FCFA) in providing safe drinking water worldwide, constructed over 2600 water points and supported 752,997 households in easing their access to potable water [1]. The right to water is a fundamental right that has been inscribed in many international conventions. But due to its ill attainment by 2015 through the Millennium Development Goals (MDGs), it was reinforced after 2015 when nations took to themselves to redefine the context governing the water sector. Thus, this objective was set out in the Sustainable Development Goals (SDGs). During the 2002 Earth Summit on Sustainable Development held in Johannesburg-South Africa, National Action Plans were elaborated for the integrated management of water resources and the efficient use of water was identified as an important aspect in the attainment of the MDGs. Nations at this conference were recommended to dispose of a protection plan and the management of natural resources for purposes of achieving social and economic development. "Water is life" so the saying goes. Water can be abundant in nature but not available for drinking. The efforts of governments coupled with technological developments are to make water potable that is available and accessible to man. It should be noted that the human body contains $70 \%$ of water. If $2 \%$ of this water is lost, then that person must be tasty and if $8 \%$ is lost, then the person faces dehydration [2]. The human body needs at least 1.5 litre of water every day. The quality of the water is therefore a pre-requisite for the wellbeing of the human body. If one can go for days without electricity and food, it is on the other hand impossible for someone to go for two days without water [3]. Thus, priority be given to domestic use of water and this necessitates efficient public service to ease access to potable water. Given all these, Cameroon just like other countries south of the Sahara has engaged in the integrated management of water resources. The guidelines in the management of water resources in Cameroon stem from a series of instruments that have been drawn from several documents, speeches, texts which demonstrates the determination of the state to improve on the living conditions of Cameroonians. This falls within the framework of "Greater Ambitions" as defined by the state policy. These instruments reveal a certain number of strategic axes that demonstrate Cameroon's progressive move towards the harmonisation of a national water policy [4].

Cameroon is endowed with a certain number of instruments and institutional organs that are charged with the elaboration and the execution of the national policy on water. This consists of Law No. 98-005 of $14^{\text {th }}$ April 1998 bearing on 
water regime which stipulates that the government can transfer part or all of its prerogatives to decentralised local collectivities. Secondly, the National Decentralisation Council (NDC) which was created by Law No. 2004/017 of 22 July 2004 empowered each local collectivity to autonomously manage natural resources for its development in order to ensure the wellbeing of its population [5] [6].

Considered as a decentralised territorial collectivity, the Nkong Zem council area benefitted from the installation of a pipe-borne water financed by Groupement d'Initiateur Communal de la Population de Bafou (GICAPBAF) in 2012. The Batsengl'a pipe borne water is subjected to various controls by different organisations that guarantee the services to the local population. There are four organisations that assure the control and follow-up, exploitation done by GICAPBAF in association with COGEREPS (an NGO). It should be noted that on the $27^{\text {th }}$ of June 2012, GICAPBAF passed over the management of this water project to COGEREPS that comprised of 28 members amongst whom there are four (4) elected by the population of the Sa'ah quarter. Apart from the bureau, there is a technical unit that ensures maintenance works in the network, three (3) persons who read the meters and distribute bills and two (2) cashiers charged with the reception of funds. The partnership agreement COGEREPS signed with GICAPBAF was on the basis that the former manages the water project while the later gets some percentage of the total amount raised per month. The agents of COGEREPS do not use any computerised system in managing this water project. It will be of advantage if a computerised system is put in place because this will facilitate and guarantee the sustainability of the project [7].

With the absence of a computerised system for this pipe-borne water project, there is the fear that in case there is a rupture of the contract with COGEREPS, a new management enterprise might not master the extension and functioning of the network. Furthermore, future generations might have difficulties in mastering the network and which can thus lead to a close down. GIS can ably respond to this worry through the creation of a database because, all the segments of the network (pipes, tanks, valves, junctions, taps etc.) will be coded in a computer using a GIS software and characterised to detect rapidly any malfunctioning at any point of the water network [8].

\section{Materials and Methods}

\subsection{The Study Area}

Nkong zem council area covers a surface area of $225 \mathrm{~km}^{2}$ and is located within the area separating Bafoussam-the West regional capital, and Dschang towards the west is characterised by a dispersed settlement spread across rolling hills with a high rural density (Figure 1). It constitutes one of the five sub Divisions that make up Menoua Division in the West Region of Cameroon. The sub

Division is divided into four main zones which include: Bafou North, Bafou Centre, Bafou South and Baleveng. This study is however limited to Bafou South 
otherwise known as Batsengl'a which covers a surface area of $9.5 \mathrm{~km}^{2}$. The whole landscape is covered by farmlands that are made up of coffee, maize, fruit trees and other food crops. The isolated hamlets concentrate on farming and sell their produce to the towns of Bafoussam, Dschang, Douala and Yaounde. GICAPBAF who initiated the pipe-borne water project for the area had as objective to ensure the wellbeing of the population and achieve rural development. It thus benefitted from the financing of "Elans" and "Tokem" to ensure an integrated management of water resources that associates agriculture and animal husbandry faced with adverse climatic conditions in the area. The first phase of the project started in 2012 with 2.2. Maintaining the Integrity of the Specifications the installation of Sa'ah Batsengl'a water project which is managed by COGEREPS [9].

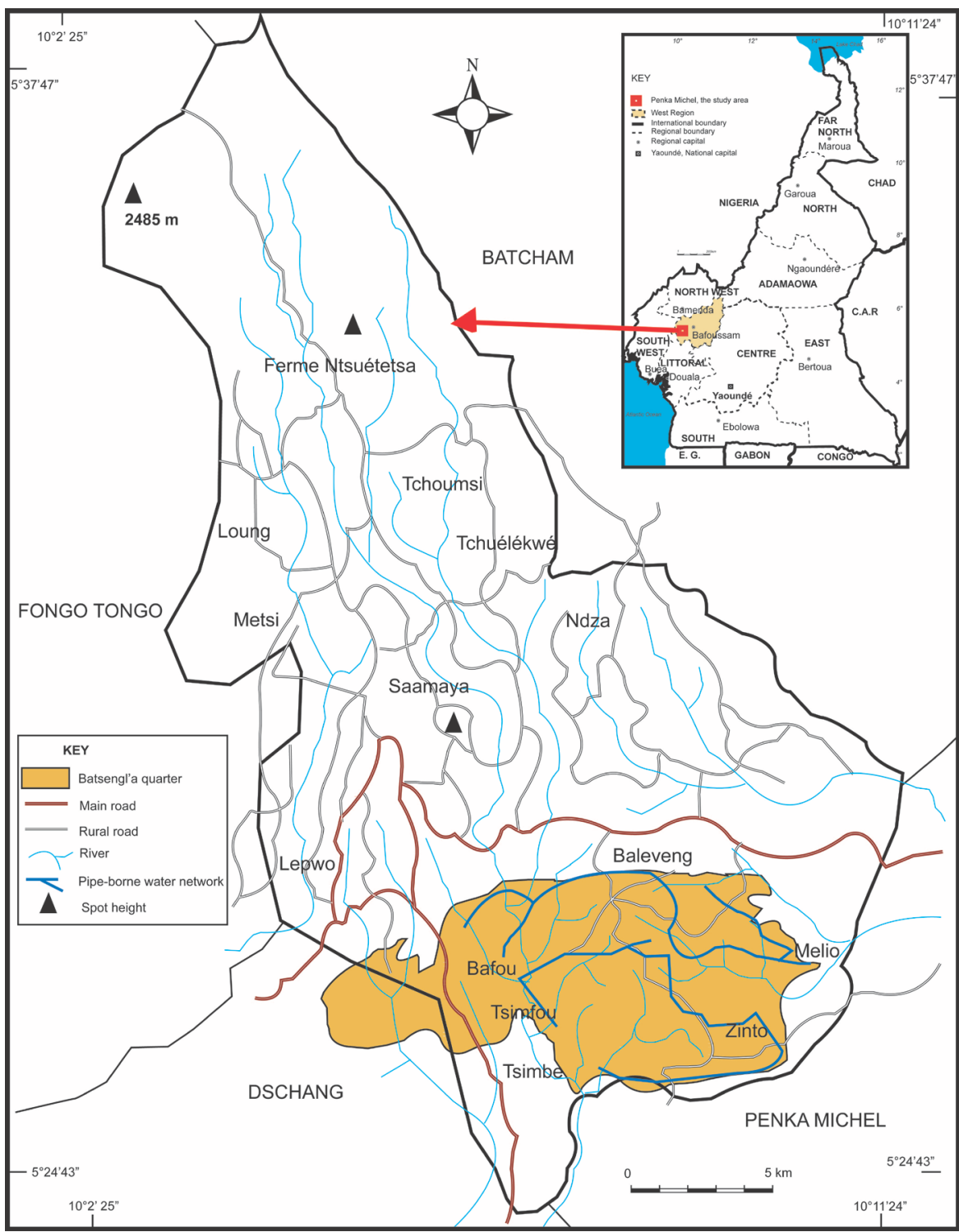

Figure 1. Location of the Batsengl'a water project area in the Nkong Zem Council area. Source: Adapted from the topographic map sheet of Bafoussam NB 32-X3. 


\subsection{Methodology Adopted}

The method adopted for this study leaves much to be desired by resource managers who are in constant search for the sustainable management of natural resources. It is therefore a tool conceived for the sustainable and efficient management of pipe borne water in a well-defined territory. The method has been structured into stages of modelling and treatment that is divided up into three deferent phases as follows:

> Collection and structuring of data (putting in place of a database);

$>$ Multi-criteria categorisation of investigations and rehabilitation; this means modelling the structure of the network in order to determine areas of malfunctioning and anomalies, decisional modelling in order to determine maintenance priorities and the rehabilitation of the network;

Implantation of the GIS Applied to Water Supply (GIS-AWS) [10].

\subsubsection{Data Collection and Structuring}

The raster data used for this study is a Google Earth image capture that covers the study area. This was then followed by visual image interpretation. On the image some time was spent to interpret the image ie identify certain objects and determine spots where GPS points could be taken to be used for geo-referencing. In this wise a pilot field trip was organised just to obtain points for the geo-referencing. These points were registered in Decimal Degrees (DD) for purposes of use in MapInfo. With the MapInfo computer software the raster image was then geo-referenced using the following projection system;

- Category-WGS 84,

- UTM zone-32 of the Northern Hemisphere,

- Units-Degrees,

- Datum-zone 32 of the azimuthal projection [11].

\subsubsection{Modelling the Hydraulic Components of Water Supply Network}

A water supply network is characterised by three main functions which include the production function, storage function and the distribution function. Figures 3-5 demonstrate the different models. In modelling the production function, it should be noted that production takes place at the level of underground water or surface water capture. The quality of the water is in function of the level of treatment (Figure 2). For modelling the storage function, this is done in reservoirs or tanks that are situated upstream at every locality in order to guarantee gravitational supply (Figure 3).

Lastly as concerns modelling the distribution function, water leaving the reservoirs in complex or ramified networks are equipped with various division valves and sector meters. This increases security and avoid interruptions during repairs. Water gets to the user through specific connections (Figure 4) [12].

\subsubsection{Conception of the Network}

Database in every computerised system constitutes one of the most important aspect given its flexibility and the quantity of the information that it can contain. 
Data is just like raw information (observation). Once treated, useful information is obtained that leads to the conception of database. These database are of different natures;

- Variable nature (geographic file), a point (gate, bore hole, reservoir); a line (pipe, route...); a surface or region (a surface, settlement);

- Variable structure: raster (satellite image, scanned image); vector (limit of a surface);

- Variable source, being table of figures (files of bore holes), maps or plans realised in the study area (plans of networks, long profiles...) [13].

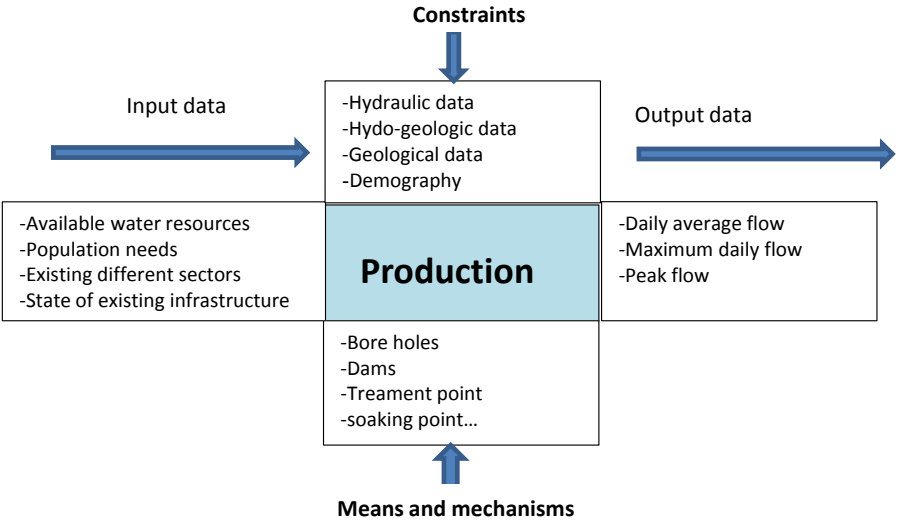

Figure 2. Modelling the production function Conceptual model.

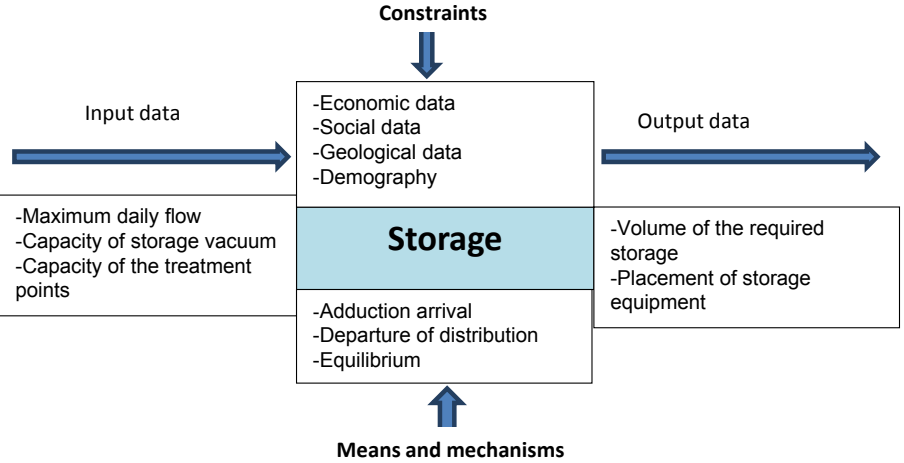

Figure 3. Modelling the storage function.

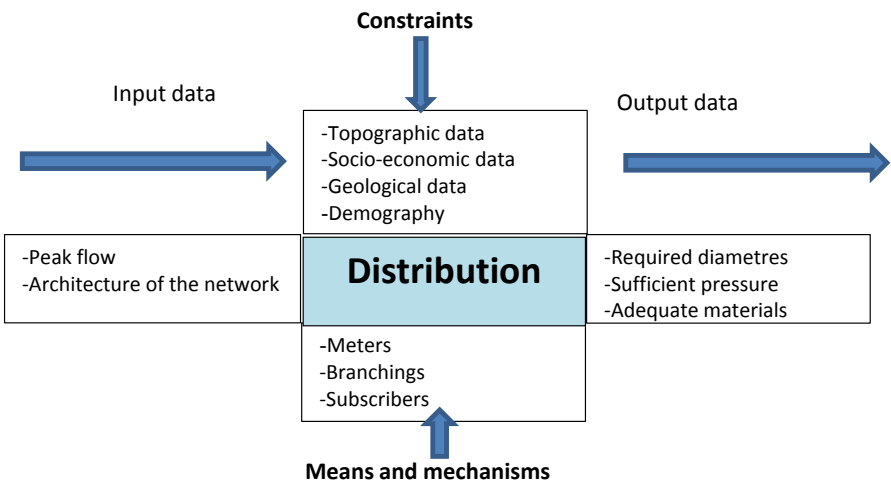

Figure 4. Modelling the distribution function. 
The associated data are organised in the form of tables. Attribute names are given field by field according to their types (character, integer, float, decimal, date ...). Each geometric entity (pipe) is linked to an exhaustive description, this link is created through an internal identifier that is commonly called primary key or index. With the use of GPS, tracking of the pipes was carried out in order to trace the pipe network on a map form easy detection of any problem in the network. This was done by two people, one concerned with the network in the north and another in the south where the separating point was fixed at Sa'ah quarter. All the tracked data was then overlaid on the geo-referenced surface and later imported into the QGIS computer software for further simulation [14].

\subsection{Procedure from GIS to Epanet}

The passing from GIS to Epanet enabled us to carry out a hydraulic simulation from GIS data within Epanet once the pipe network was traced. To this effect, a file "inp" (text file) was developed which could be interpreted for pipes, pumps, reservoirs, tarpaulins and valves for the network. Before exporting the "inp" file, QGIS provides the possibility of launching a simulation to ensure that the network will be modelled without any error once it is imported into Epanet. Topological control of the network before the launching of the simulation was necessary. However Epanet does not tolerate topological error in the execution of a hydraulic simulation. Topology here refers to the following aspects:

- Interruption of the pipes at the right of every intersection,

- No superposition of objects conveyed;

- No multi-parts objects conveyed

- Verification of the connectivity of pipes one after another at the valves

The passing from GIS to Epanet was realised thanks to the use of GHydraulics plugin of QGIS. GHydraulics let to the analysis of the water supply network through the use of

Epanet. This was ensured by the exportation of the "inp" file which had been interpreted by Epanet and its simulation on QGIS [15].

\subsection{Study of Possible Scenarios}

The simulation system here results from the study of different scenarios which include the behaviour of the network during peak periods of water usage (mornings and evenings) and simulation scenarios during recess periods (afternoons and nights). Figure 5 demonstrates geometric and hydraulic characteristics of channelling number 5 pipe after a week simulation.

\subsubsection{Coupling Epanet with GIS}

The passage from Epanet to GIS was realised thanks to inpshp tool which is an element of inptool package of Epanet. This comprises of a documentation and supplementary tools that handle inp Epanet files. Inp tools contextual menu can be opened with just one right click on the inp file in Windows Explorer. Shp2inp converts all the inp files that represents water network used in analysing the hy- 
draulic under Epanet and an assembly of $s h p$ files for further geo-treatment using a GIS software. This conversion only concerns the components of the network such as the pumps, pipes, tanks, valves and tarpaulins. On Figure 6, one finds how an inp file is converted to shp file. After clicking on "create shapefile" a new directory is defined for storage (Figure 6). The converted files cannot directly be interpreted in MapInfo thus there was need for them to be converted to a table in order to enable MapInfo read them. To this effect only the universal transversal tool of the MapInfo software could be used to do the conversion. (Figure 7) [16] [17].

The corresponding results of the converted files in .tab (MapInfo table) converted from universal translator are presented as follows (Figure 8).

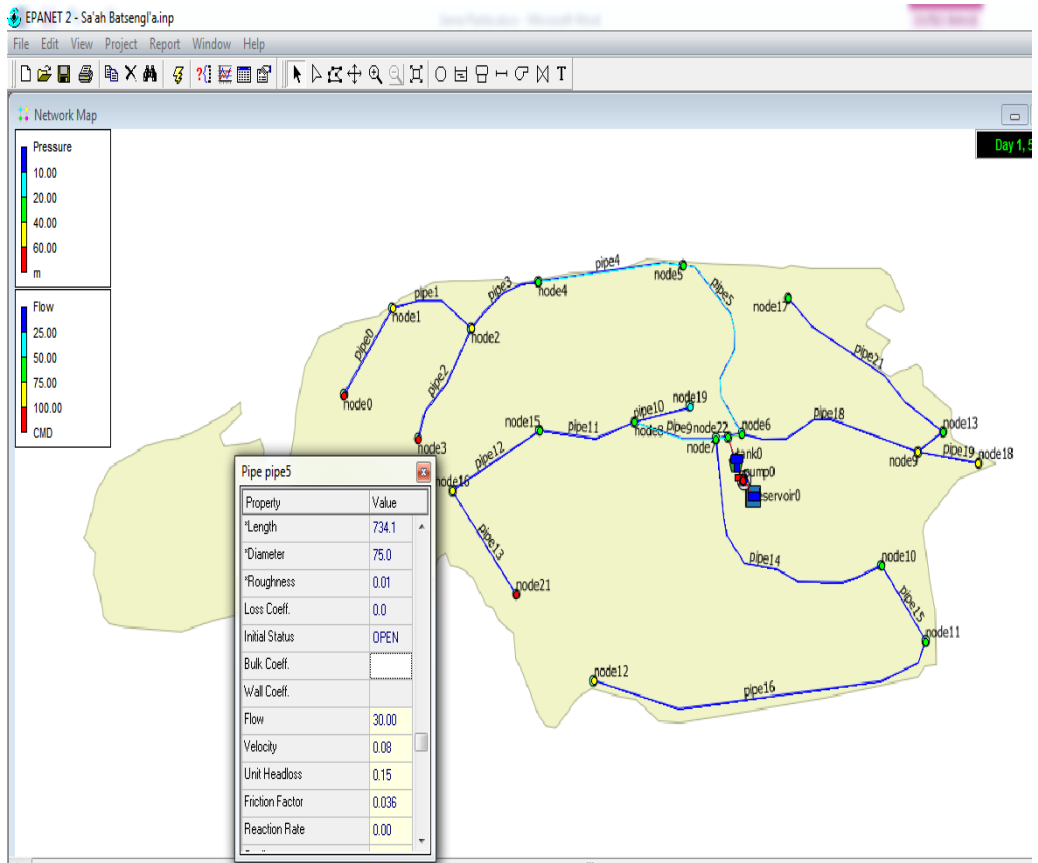

Figure 5. Geometric and hydraulic characteristics of channelling number 5 pipe.

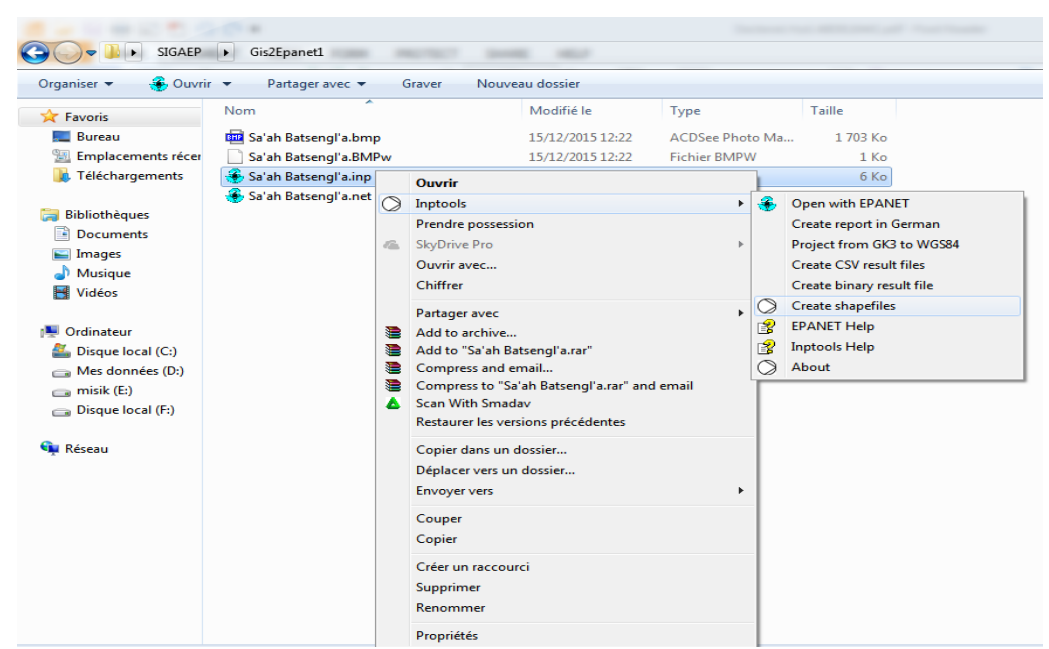

Figure 6. Stages of obtaining shapefile. 


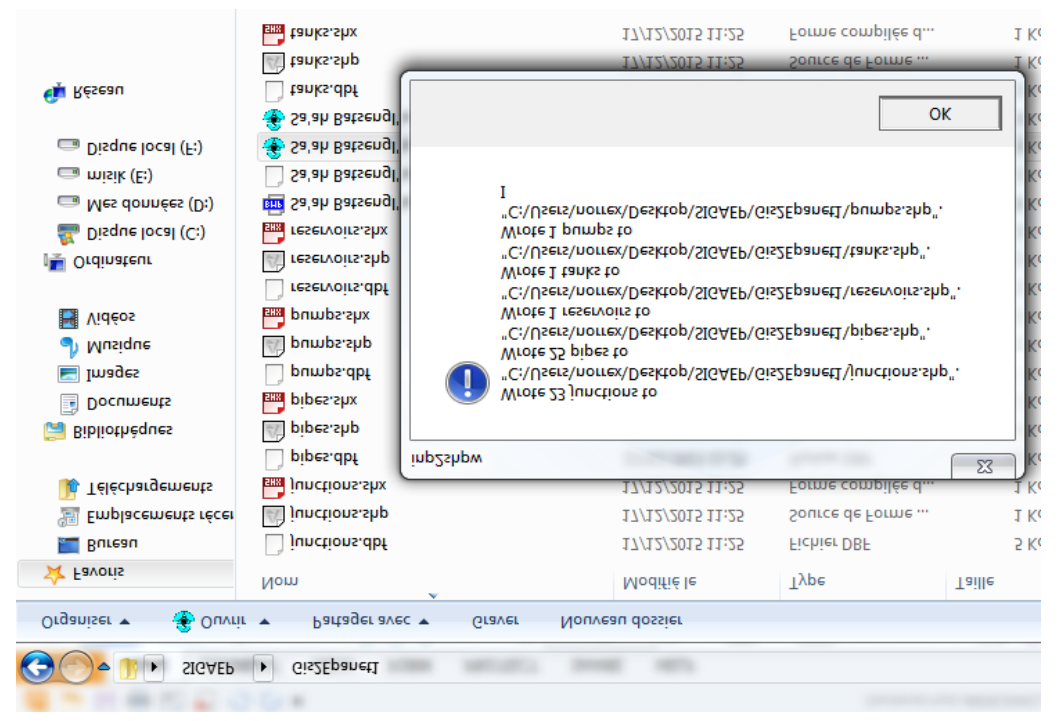

Figure 7. Converting inp file in Epanet to $s h p$ file.

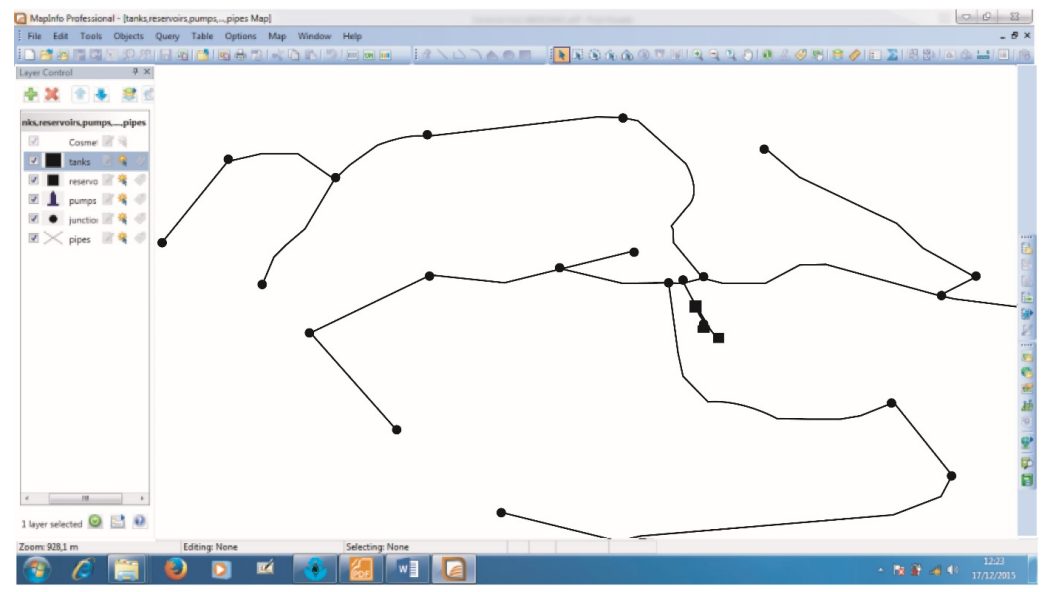

Figure 8. Result after passing from Apanet to GIS.

\subsubsection{Procedure of Implementing GIS-AWS}

Choice of programming language:

MapBasic was chosen because it is ideal for customising MapInfo applications. It integrates the standard language of SQL queries which enables the easy manipulation of tables or database entities. MapBasic programmes can be executed in the MapInfo (. $m b x$ ) environment. It provides an environment for the development of programmes in the specific language which can directly be executed and the results visible on MapInfo. Editors such as MapBasic IDE provides a comfortable and easily manipulated environment. Using universal translator of the Mapinfo software, these files can be converted to shapefiles.

\section{Application of GIS-AWS for Monitoring and Managing Nkongzem Water Supply Project}

With a population estimated at 53,367 inhabitants (BUCREP, 2005) the two main communities to be covered by the project when completed include Baleveng 
and Bafou. For the first phase already completed is the south of Bafou Sub Division called Batsengl'a. With an annual population increase of about $2.8 \%$, it is expected that by 2035 (year the Cameroon government has earmarked to attain emergence) the population will attain 122,201 inhabitants, a figure that can guide prospective extension of the pipe-borne water project.

\subsection{The Existing Functioning of the Pipe-Borne Water Project}

This pipe-borne water distribution measures $18 \mathrm{~km}$ long of which $17 \mathrm{~km}$ consist of the distribution pipes and $1 \mathrm{~km}$ of water adduction. The diameters of the pipes distributing the water vary between 27 to $75 \mathrm{~mm}$ while those for the water adduction is $50 \mathrm{~mm}$. The Batsengl'a water distribution network is equipped with a tank of $12 \mathrm{~m}$ high of $15 \mathrm{~m}^{3}$ volume. Its capture site is located at Sa'ah Ketsop with a depth of $8.40 \mathrm{~m}$ with water level observed at $4.30 \mathrm{~m}$ in November 2012, a pump of $2.2 \mathrm{~kW}, 95 \mathrm{~m}$ high, $1.5 \mathrm{~m}$ long and pumping at $5 \mathrm{~m}^{3} / \mathrm{h}$. Added to this is a potable water tank of $12 \mathrm{~m}$ high with $25 \mathrm{~m}^{3}$ capacity, 17 main connections with 13 functioning at full capacity on 6 taps. The performance of the pipe-borne water project was generally satisfactory at the beginning. During the 2013-2014 year, performance rate stood at $67 \%$ with an average of $450 \mathrm{~m}^{3}$ of water consumed monthly while $177 \mathrm{~m}^{3}$ registered as losses. By that year too, the number of good functioning connections rose from 13 to 16. Since the putting in place of the project, water has constantly been flowing on public taps as well as in the private homes that had been installed. In spite of the leakages observed here and there, water consumption has been stabilised in the locality and the old habit of covering long distances to fetch for potable water even of doubtful quality has all been forgotten.

\subsection{Application of the GIS-AWS}

GIS-AWS is an application system developed to sustainably manage the pipi-borne water network in Sa'a Batsengl'a. This started with the mapping out of the network within the space and develop a database that can easily be understood by successive management authorities thereby giving way for sustainable management. In order to computerise the system the following applications were developed;

\section{- Distribution of speed}

This application enables the display of a thematic map following the distribution of speed as shown on Figure 9.

\section{- Distribution of flow}

This application enables the display of a thematic map following the distribution of flow as shown on Figure 10.

\section{- Presentation of database}

It is presented as can be seen on Figure 11.

\section{- Examples of the SQL queries}

The GIS that has been developed to manage the Sa'ah Batsengl'a water supply enabled the analysis of the network following different criteria which include diameter of the pipes, type of construction materials, nature and age of pipes. 
Figure 12 and Figure 13 illustrate examples of a query.

$\begin{array}{ccc}\text { SELECT }^{*} & \text { FROM PIPE_LIN } & \text { WHERE DIAMETRE_MM= "30"; } \\ \text { SELECT }^{*} & \text { FROM PIPE_LIN } & \text { WHERE MATERIEL= "PVC". }\end{array}$

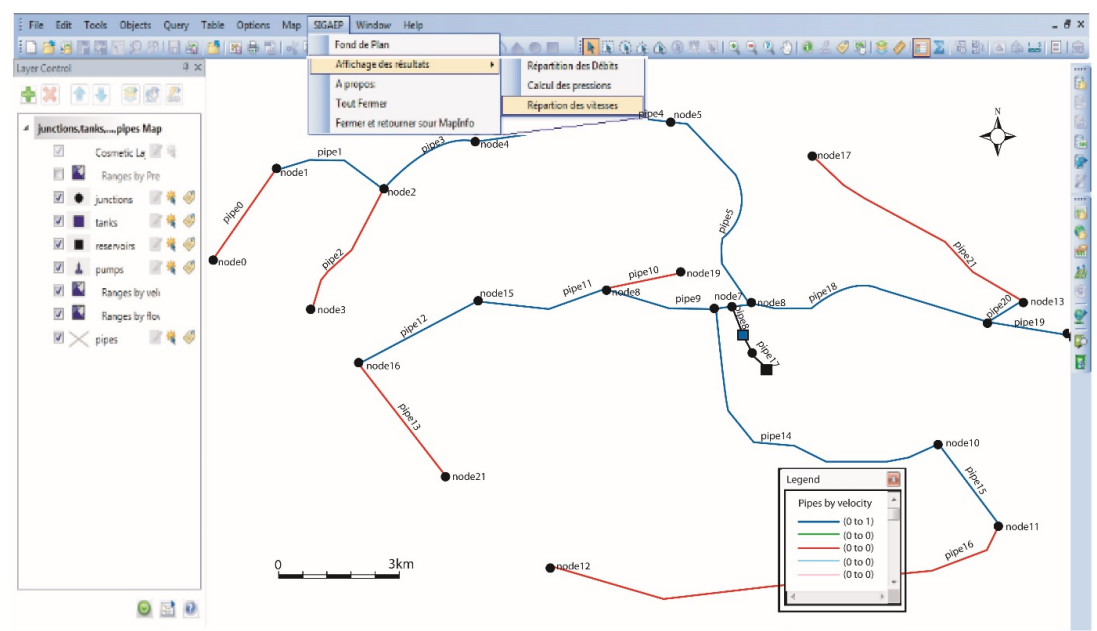

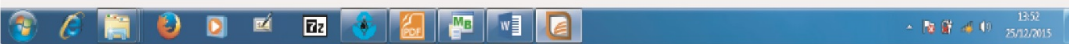

Figure 9. Distribution of speed in the pipes.

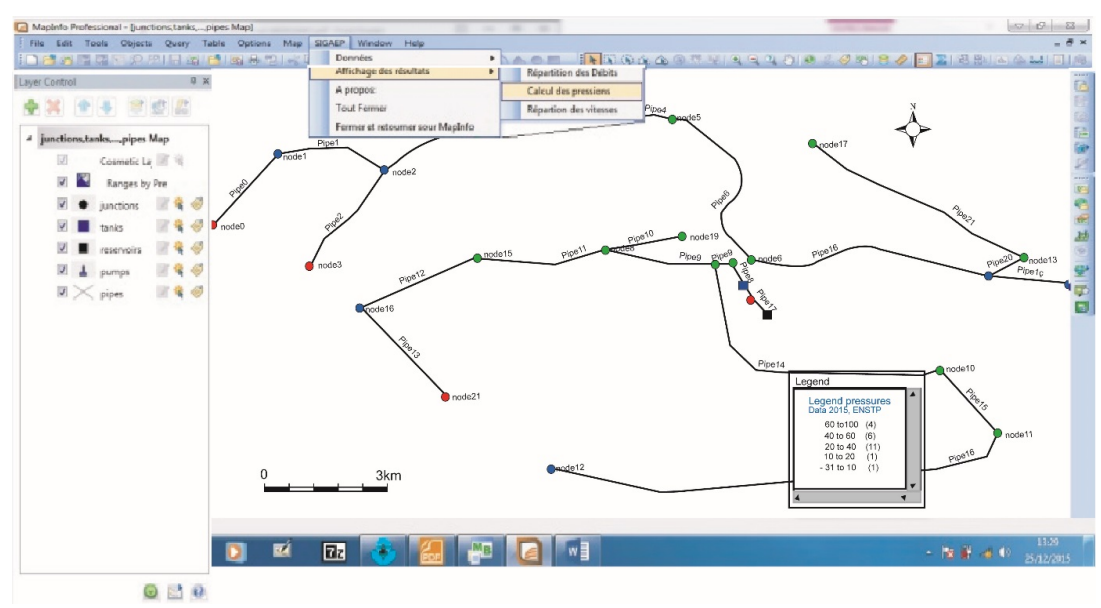

Figure 10. Distribution of flow in the pipes.

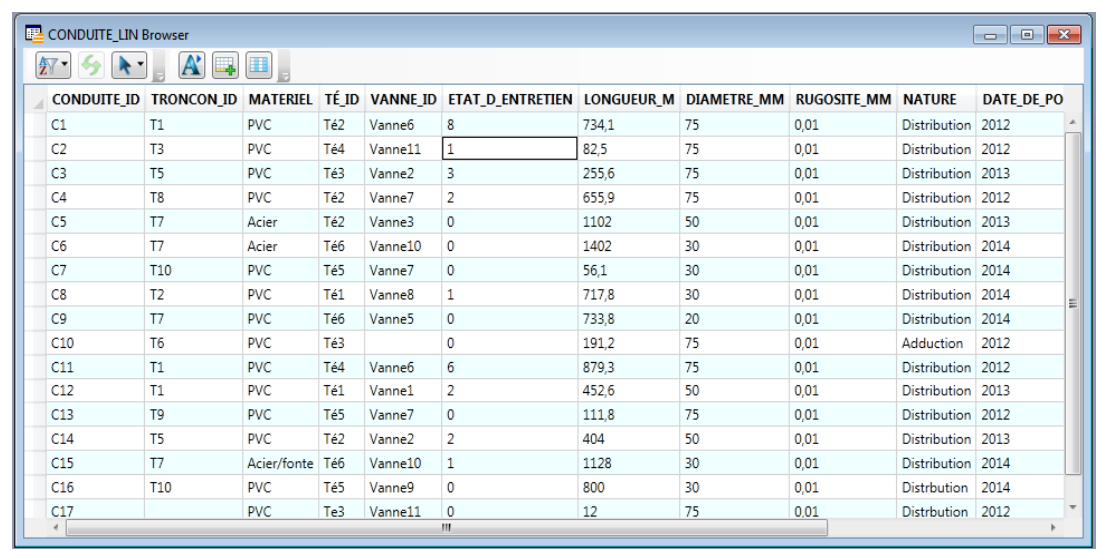

Figure 11. Structure of the "pipe" table. 


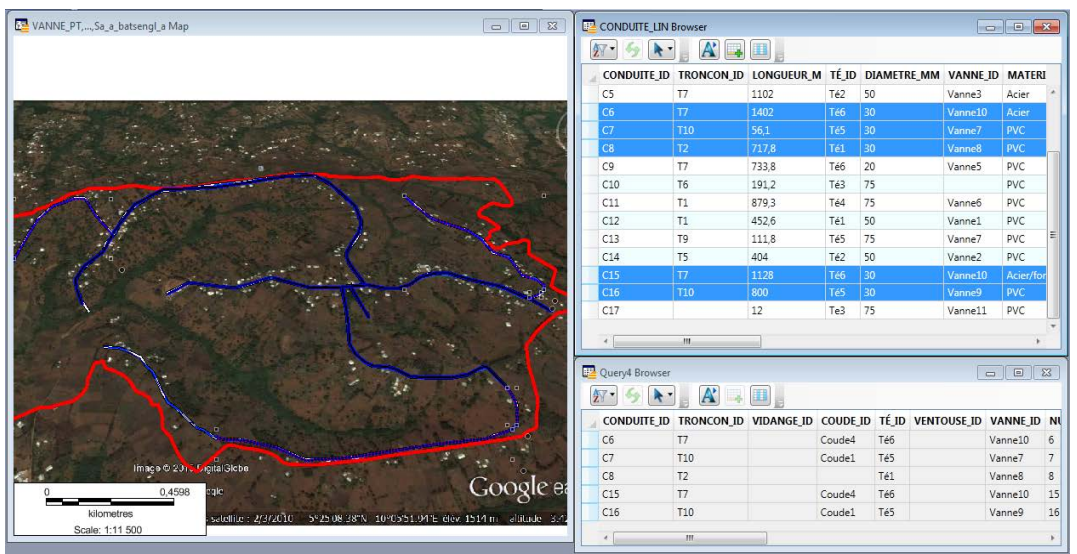

Figure 12. Result of query for the pipes of a diameter $30 \mathrm{~mm}$.

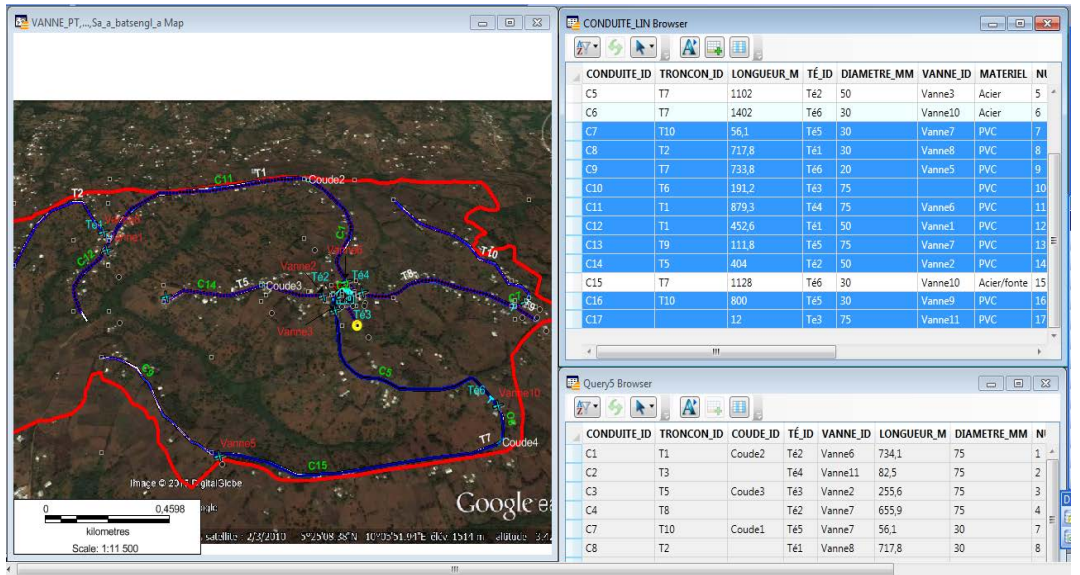

Figure 13. Result of query for the pipes PVC material.

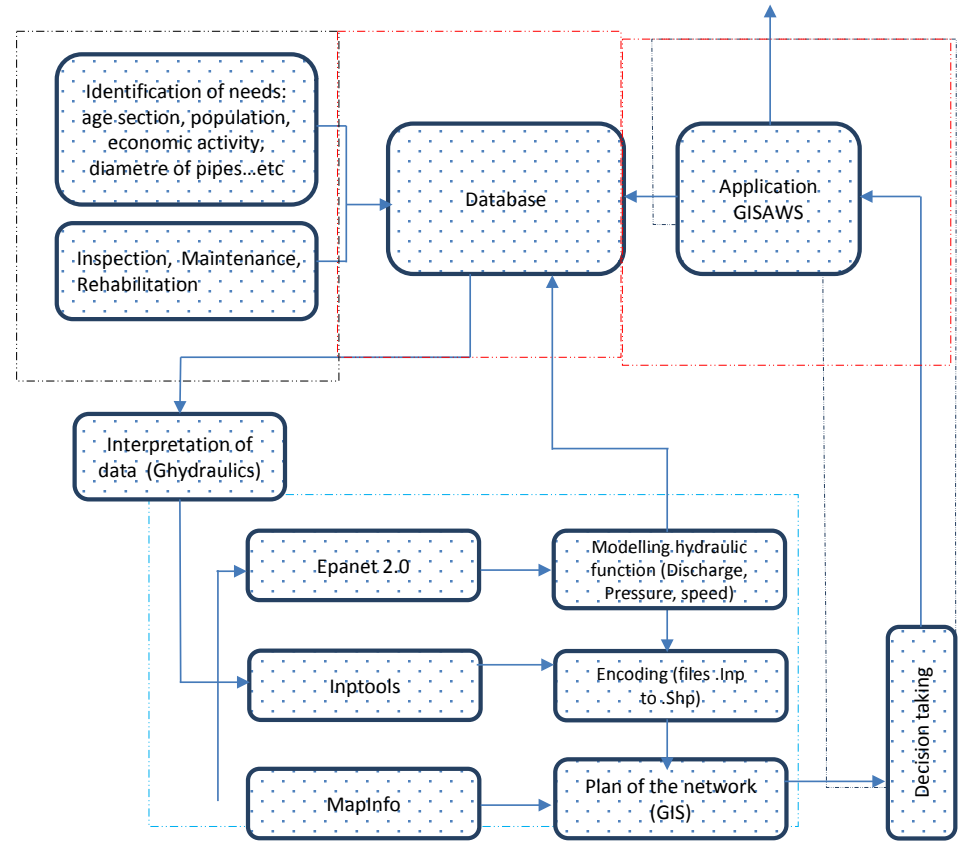

Figure 14. Modelling sketch of GIS Applied to Water Supply (GISAWS). Source: Authors' conception, 2018. 
From Figure 13 one finds a selection of the different attributes of the pipe table given that the diameter of the pipe is $30 \mathrm{~mm}$ in the whole network. While in Figure 14 one finds the selection of different attributes of the pipe table given that the material used is PVC (plastic) in the whole network [18].

\subsection{GIS-AWS Modelling}

Figure 14 demonstrates the entire GIS-AWS model for the Batsengl'a water network.

Once a simulation succeeds, many attributes are automatically added to the table for valves, pipes, pumps, tanks and tarpaulins thanks to the use of the simulation algorithm "Epanet". Figure 15 illustrates the contents of the table for pipes encircled in red when simulated.

GHydrualics has the function of calculating the diameter of pipes given the amount of water discharged. The functioning of this application provides that the volume of water consumed monthly will pass from $450 \mathrm{~m}^{3}$ to about $600 \mathrm{~m}^{3}$. The amount of water lost will fall from $177 \mathrm{~m}^{3}$ to less than $80 \mathrm{~m}^{3}$ per month. Though great water losses were registered in 2013 according to Olivier Gente and VSI Elans [7] the annual production remained as low as expected standing at $47 \%$ (i.e. $798 \mathrm{~m}^{3}$ consumed as against $903 \mathrm{~m}^{3}$ lost). To this effect, the water project now endowed with an efficient and sustainable management system this will improve upon the quality of the services rendered to subscribers, increase the number of subscribers, facilitate the collection and assembly of information linked to the geographic location of the distribution network in an interactive computerised support. Though this low production capacity cannot be linked to the absence of a computerised system, its putting in place will boost both the quality and quantity of water accessible to more than $90 \%$ of the Batsengl'a population. The activities of the technical unit charged with maintenance works in the network will greatly be facilitated as a gap of 1 hour is sufficient to signal a malfunctioning within the network. Since the computerised system codes from the storage tank, through the adduction to the distribution pipes, valves and tarpaulins, the technical unit that masters the various sectors can intervene timely which can stabilise the output [19].

\section{Results Analysis}

If a project as such is well conceived and well managed, the local population stands to benefit from it, but if is ill conceived or poorly managed, it rather creates a problem than solving it. Most governments in African countries south of the Sahara have often found it difficult, if not, impossible to provide the rural areas with pipe-borne water. With this difficulty, these countries keep battling with the phenomenon of rural exodus. It should be noted that the Nkong Zem council area records one of the highest out migration zone in Cameroon. Most of the people move to Douala and Yaounde where they work and raise gigantic traditional halls called "foyers". They meet in these halls on regular basis where 


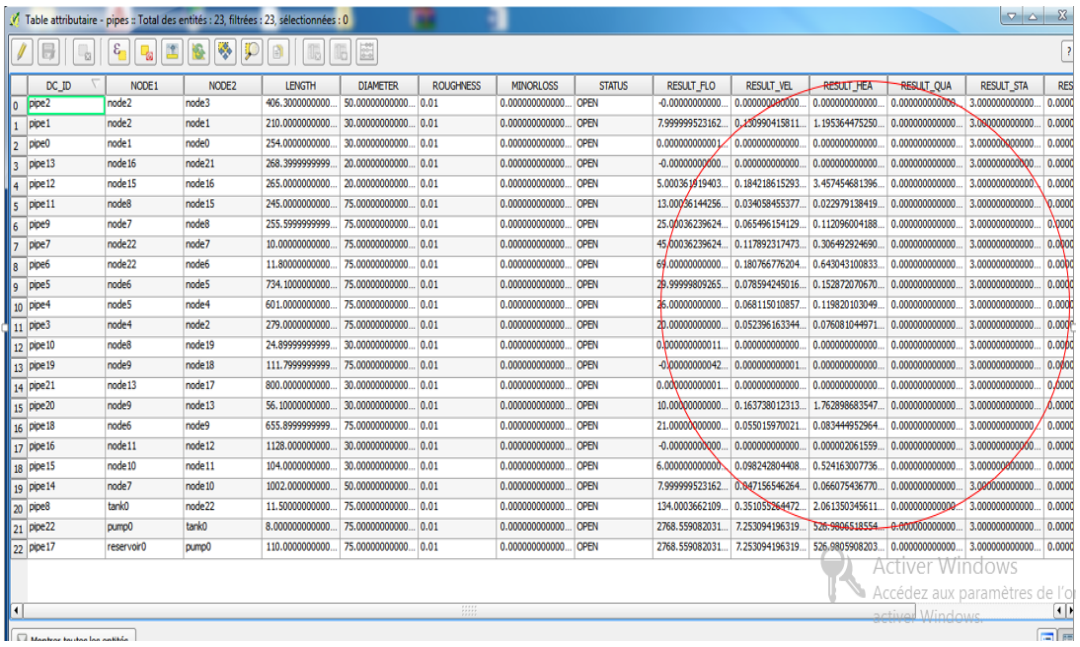

Figure 15. Presentation of the table for pipes after simulation on QGIS via GHydraulics.

money is raised for development back at home. Most young people once they can no longer go to school leave the village to settle either in these two cities to do business. It is through this background that GICAPBAF decided to finance the setting up of pipe-borne water in the area mainly for two reasons: [20]

- So that the rural people could now have safe potable water beside them since this has been a serious problem throughout the history of the people;

- To reduce in a significant manner out migration from the area and at the same time encourage return migrants who could contribute in fostering the development of the area.

This private initiative stems from the provisions provided by law No. 98-005 of 14 April 1998 by the Cameroon government. This law gives room for private bodies to venture in the domain of potable water even if this is for profit making. The initiative of GICAPBAF was a welcome relieve to the local population as the project benefited from government support through subvention that contributed up to $21 \%$ of the total cost of the project [21].

In the course of analysing the pipe-borne water network in the GIS, SQL queries have been set up in the system. For example to analyse the result using the SQL query facility for example SELECT * FROM PIPE _LIN, WHERE DIAMETRE_MM= "30; type=private? (public?)"; (Figure 12) it will happen that the choice of the diameters of pipes is 30 " based on what was proposed by suppliers. Given the large amount of water discharge to be conveyed by the distribution pipes, they are hardly more than $75 \mathrm{~mm}$ in the rural areas. The different diameters of pipes used in the Batsengl'a water project are $75 \mathrm{~mm}(47 \%), 50 \mathrm{~mm}$ (18\%), $30 \mathrm{~mm}(29 \%)$, and $20 \mathrm{~mm}(6 \%)$. Those of private connections are not taken into consideration. The use of pipes of $75 \mathrm{~mm}$ diameters is proof of the posterity of the project but whose sustainability could only be guaranteed with the provision of cartography and database.

In the second example (Figure 13) to analyse the result with the use of this SQL query facility SELECT * FROM PIPE _LIN, WHERE MATERIEL= "PVC", it will show that the material used for the pipes in the Batsengl'a pipe-borne wa- 
ter project is PVC. This has the advantage that it is flexible and resistant. PVC in the Batsengl'a water project constituted $82 \%$ and $18 \%$ steel installed in the fragile areas of the zone in order to avoid all forms of external accretion [22].

\section{Discussion}

This proposed tool, if implemented as the Sa'ah Batsengl'a council authorities assures will act as a pace setter and a laudable initiative that should be emulated by other rural communities especially in West Cameroon where settlement is dispersed. Local personnel will be trained and their direct involvement in such a project will certainly guarantee sustainability. This will avoid the cropping up of management crisis as has always been the case that precipitate their closure. For example SCAN WATER project introduced in Cameroon in the 1980s and financed by the Canadian government could not resist for two years in many villages of rural Cameroon. The greatest benefit that the rural communities drew from the SCAN WATER project is that the base for pipe-borne water was created thus for any future such installations, these very pipes or the same channels could be used [23].

The provision of cartography and database for the Nkong Zem water project to a certain extent marks a milestone in the installation of a sustainable pipeborne water in this rural area. This database provides for the registration and provision of a code to every tap, valve, pipe, junction, meter, tank, etc. Besides, every size, length and material of the pipe registered and coded. It is simply the use of the codes in the interaction system that action is determined at any given point of the network [24].

Before the putting in place of the project, the following constituted sources of potable water to the local population as provided by the 2005 census in Cameroon, (Table 1).

Table 1. Sources of potable water in Nkong Zem Sub Division before the installation of the pipe-borne water network.

\begin{tabular}{ccc}
\hline No. & Sources of potable water & Number of people concerned \\
\hline 1 & Internal tap & 91 \\
2 & External tap & 915 \\
3 & Improved well & 1314 \\
4 & Unimproved well & 498 \\
5 & Public paid tap & 346 \\
6 & River/rain water & 6732 \\
7 & Bore hole & 895 \\
8 & Mineral water & 48 \\
9 & Controlled spring & 1037 \\
10 & Lake/Pond/Swamp & 17 \\
11 & Others (to be precised) & 16 \\
12 & Undetermined & 16 \\
& Total & 12,360 \\
\hline
\end{tabular}

Source: BUCREP, 2005 [19]. 
Sources such as bore holds, springs, river/rain water and wells provided potable water to about $70.15 \%$ of the population, while controlled sources with acceptable quality of drinking could barely satisfy $29.85 \%$. Apart from using the fresh water for drinking, much of this water is used for the watering of crops in low lying areas during the dry season. The water points that are managed in the area benefited from government subventions, that is, from the Public Investment Budget but which lack a maintenance policy and have been abandoned. This therefore means that with the putting in place of the pipe-borne water even through a private initiative can still lack proper follow-up and maintenance policy. If that is not the case it might still suffer from abandonment just like some managed water points.

From the above reason therefore, providing pipe-borne water with an interactive map, (GIS-AWS) coupled with a database will not only ensure the sustainability of the management, but will greatly enhance the maintenance of the equipment and output. No matter when a staff member is recruited to work for the project, it will become easy for him/her to know the location of valves, branches, taps and meters since they have been computerised using the a GIS software and modelled in a GIS-Epanet. With GIS-AWS, regular and systematic checks of meters that are coded in a computerised system will enable the enterprise to master the output of each branching, knots, valves, and the functioning and malfunctioning of the whole network. This will lead to prompt action in case the output of a specific point is below expectation, leakages, destruction or pirating of any part of the network. In this wise, one has no doubt that the sustainability of the system will be guaranteed.

Apart from the implementation of a database for the network, the management committee should have a mandate that is well determined. This management committee has an audit bench where cases of mismanagement or performance level is discussed [25]. The management committee is led by a manager who reports any problem to the committee at well-defined periods of the year. It is through this reflection that the manager quickly reported the case of a drastic cut in the amount of water consumed per day which passed from 4.5 $\mathrm{m}^{3} /$ day in 2012 to $1.5 \mathrm{~m}^{3} /$ day in the first quarter of 2013. Explanation given for this drastic drop was that there were serious leakages and siltation in the tank. Furthermore, the supply pipes into the tank were not functioning to full capacity. The early detection of these problems also prompted the reparation which thus stabilised the flow of water since June 2013 which stood at $4.2 \mathrm{~m}^{3} /$ day. Though this is still lower than the expected amount per day according to the laid down norms $\left(15 \mathrm{~m}^{3} /\right.$ day), ensuring its sustainability becomes very important. This low output is generally attributed to:

- Insufficient appropriate material used for the detection and repairs of water leakages;

- Wrong spare parts acquired for the replacement;

- No maintenance policy for the network; 
- Many leakages with no prompt repairs at individual branching.

All these problems have been analysed and measures taken to improve and stabilise the output.

\section{Conclusions}

This work constitutes a tool to ease decision-making in the management of pipeborne water supply in a given locality. Thus, it constitutes the development of Geographic Information System (GIS) for the management of Sa'ah Batsengl'a pipe-borne water project. It offers to network operators a powerful management tool, with a relational database that can be interrogated at any time. In the same vein, for any analysis of malfunctioning, an instant response can be given. Also, it facilitates the programming of intervention that can be performed at any point on the network. It is simply a tool of exploitation which allows any managing body to perform the diagnosis of the network in order to detect any problem cropping up for fast solutions to be taken.

Considering the available data, hydraulic performance (pressure, speed, flow...) of the network of Sa'ah water project was taken into consideration, which led to the coupling between the GIS (QGIS) and Epanet model as well as the coupling between Epanet and GIS MapInfo [26].

The results showed that, the network of Sa'ah must be restructured, the rehabilitation operations are essential to correct the pressures related problems at the network level. Also, the establishment of a new pump is essential to ensure relay in case of malfunctions. Accessory organs must be provided to limit excessive pressure, main cause of leakages occurrences and the installation of sector branches.

From the meters, one can predict the section where there is a leakage and of course intervene. The keyboarding operations, storage and data update to store up the history of exploitation problems (breaks, renewal, modification of the route...) for forecasts of interventions on the network is essential. The advantages of such a system are not to demonstrate, but to collect and enter data that constitutes an enormous task.

Thus, the method used to develop the database for the Sa'ah water network gives rise to system analysis and an understanding of its operation, analyse all the processes associated with the network. This approach integrates a system of potable water supply of Sa'ah in an integrative nature that allows a relevant vision in relationship to the objective of the designer and the operator by modelling the overall behaviour of the system in his environment [27] [28].

This work is a first step of a global process whose goal is to develop techniques to support the management of urban and rural networks in general, and Potable Water Supply (PWS) Networks in particular, by means of a Geographic Information System. Several lines of research are to be developed to improve the model proposed for the Nkongzem Council Area (NCA), namely:

- Development of a model of consumption for the NCA, 
- Modelling quality of the water in the network,

- Correct, complete and update the background,

- Complement and update the NCA drinking water supply systems,

- Complement and update the database with the information deemed reliable and useful,

- Create a database for customer service and development [29].

\section{Acknowledgements}

We are grateful to the partnership that exists between the University of Padova in Italy and the National Advanced School of Public Works Yaounde Cameroon. It is through this convention that a professional masters on water management and sanitation has been put in place where this study benefited from partial subvention. We also want to thank Pr Nkeng Georges Elambo, the Director of the National Advanced School School of Public Works Yaounde who followed up the progress of this study to give it a keen attention. Lastly, we are grateful to the Mayor of Nkong Zem council, Mr Chedog Aboubakar for letting us have access for consultation to all the necessary documents related to this study and the embracement of the project which he terms it a welcome relief to his council. All the financial proposals made in this study saw the total approval of the mayor which will however set the base for the first database set up to manage a water project. In fact this project is first of its kind which is expected to be emulated by others in the West Region in particular and in Cameroon in general.

\section{Conflicts of Interest}

The authors declare no conflicts of interest regarding the publication of this paper.

\section{References}

[1] Gomella, C. (1985) Guide on Water Amelioration in Urban and Rural Agglomerations. Volume I: The Distribution. (Edition Eyrolles) Paris, 227 p.

[2] Moussa, M. (2002) Alimentation en eau potable. http://www.scribd.com/doc/206587295/Poly-Alimentation-en-Eau-PotableMoussa2002\#scribd

[3] Pangire (2009) Etat des lieux du secteur: Cadre législatif, réglementaire, institutionnel et ressources humaines. $236 \mathrm{p}$.

[4] Banque Africaine de Développement (2010) Project on Potable Water Supply in the Rural Milieus Country Cameroon. 101 p.

[5] Global Water Partnership Central Africa (2010) Studies on Finance Sources in the Water Sector in Cameroon for the Creation of FORSEAU. $134 \mathrm{p}$.

[6] Global Water Partnership (2004) Catalysing Change: A Handbook for Developing Integrated Water Resources Management (IWRM) and Water Efficiency Strategies. Stockholm, Elanders, $52 \mathrm{p}$.

[7] Olivier Gente, VSI Elans (2014) Bilan des activités, Réseau AEP de Sa'ah Batsingl'a dans Bafou Sud (OUEST Cameroun) [Polycopie]. $80 \mathrm{p}$.

[8] Abednego, B., Caloz, R. and Collet, C. (1990) The Use of GIS in Surface Hydraulic 
Modelling. Geographica Helvetica, 45, 161-167.

https://doi.org/10.5194/gh-45-161-1990

[9] CEPDEL Dschang (2008) Rapport démographique de la Commune de Nkong Zem. [Polycopie]. 33 p.

[10] Cherqui, F., Baati, S., Chocat, B., Le Gauffre, P., Granger, D., Loubière, B., Werey, C., et al. (2011) Outil Méthodologique d'aide à la Gestion intégrée d'un système d'Assainissement-Approche systémique du système de gestion des eaux urbaines, Rapport de Projet de recherche financé par l'ANR, Programme de Recherche Villes Durables 2009. 32 p.

[11] Choux, B. (1990) Modelling Potable Water Network Compatibility with Computerised Cartography, Water-Industry-Nuisance. 48-50.

[12] Groupe Dupont, GEOPOINT (1994) SIG, analyse spatiale et aménagement, Avignon, Université d'Avignon, Avignon, France, $231 \mathrm{p}$.

[13] Laurini, R. (1993) Databases in Geomatics (Edition Hermes). 339 p.

[14] IAAT (2003) Cahier méthodologique sur la mise en œuvre d'un SIG. 34 p.

[15] EPANET 2.0 (2011) Hydraulic Simulation and Quality for Water Network under Pressure. Users' Guide, $222 \mathrm{p}$.

[16] Vincent, C. (2012) Approche systémique et méthode multicritères pour la définition d'un système d'indicateurs de performance. Travail de Thèse de doctorat en Génie Industriel, Université de Savoie, Chamberry, 219 p.

[17] Le Moigne, J.-L. (2006) La théorie du système général-Théorie de la modélisation, Publication de l'édition 1994. Nouvelle presentation.

[18] Tabesh, M. and Delavar, M.R. (2003) Application of Integrated GIS and Hydraulic Models for Unaccounted for Water Studies in Water Distribution Systems. In: Advances in Water Supply Management, Proceedings of the CCWI 03.

[19] Didier, A. (2012) Développement d'une approche systémique du parc immobilier pour l'amélioration de sa performance énergétique. Actes des $30^{\text {ème }}$ rencontres universitaires du génie civil, Concours jeunes chercheurs-prix René Houpert, Chambéry, 6-8 juin 2012, 24-31.

[20] MINATD (2013) Practical Guide on Cooperation and intercommunal solidarity in Cameroon. $52 \mathrm{p}$.

[21] Agence Française de Développement (AFD) (2012) Etude sur les rendements des réseaux d'eau potable des communes, Etat des lieux. $4 \mathrm{p}$.

[22] Agbar, SATEIG (2014) Etude de diagnostic pour la réhabilitation des réseaux AEP de Ain Temouchent. Journée mondiale de l'eau. 16 p.

[23] PSEAU (1998) Research Action No. 8. Water Management and Protection of the Resource in Cameroon. Final Report: Water Supply Programme in Peri-Urban Quarters and Small Centres. 180 p.

[24] Laraki, L. (2010) Problématique de l'AEP et l'assainissement en milieu rural en liaison avec la qualité de l'eau. $16 \mathrm{p}$.

[25] Board Meeting of the United Nations Development Program (UNDP) and United Nations Fund for Population Activities (UNFPA) (2013) Project of the Descriptive Program for Cameroon (2013-2017). 8 p.

[26] Dimitri, S. and Bakary, D. (2007) The Use of Geographic Information Systems in Institutes/National African Bureau of Statistics. African Statistical Journal, 5, 161-181.

[27] Emmanuel Ngnikam, B. and Mougoue, F.T. (2007) Water and Sanitation and Impact on Health: Case Study of an Urban Ecosystem in Yaounde. 14 p. 
[28] Christian, G. (2011) Eau potable: Réduire les coûts à tous les niveaux, l'eau, l'industrie, les nuisances, No. 346. 96 p.

[29] de By, R.A., Knippers, R.A. and Georgiadou, Y. (2004) Principles of Geographic Information Systems, ITC Educational Textbook Series. 3rd Edition, Enschede, Holland, $226 \mathrm{p}$. 